\title{
Analgesia Induced by Dietary Restriction Is Mediated by the $\kappa$-Opioid System
}

\author{
Mercedes de los Santos-Arteaga, Sergio A. Sierra-Domínguez, German H. Fontanella, José M. Delgado-García, and \\ Ángel M. Carrión \\ División de Neurociencias, Universidad Pablo de Olavide de Sevilla, 41013 Sevilla, Spain
}

Progress in the control and treatment of pain may be facilitated by a better understanding of mechanisms underlying nociceptive processing. Here we show that mice subjected to an intermittent fasting diet (IFD) display markedly reduced responses in models of thermal and visceral pain compared with mice fed ad libitum (AL). Pharmacological analyses suggest that a change in the endogenous $\kappa$-opioid system underlies IFD-induced analgesia. The levels of prodynorphin mRNA and $\kappa$-opioid receptors in the spinal cord are higher in IFD than in AL mice. Furthermore, in spinal cord nuclear protein extracts, the activity of the transcriptional repressor DREAM (downstream regulatory element antagonist modulator), the main regulator of prodynorphin expression, is lower in IFD than in AL mice. Finally, c-Fos expression in dorsal spinal cord after noxious stimulation is significantly lower in IFD than in AL animals, indicating that dynorphin could block nociceptive information at the spinal cord. These results suggest that dietary restriction together with administration of $\kappa$-opioid agonists could be useful as a new therapeutic approach for pain relief.

Key words: c-Fos; DREAM; dynorphin; intermittent fast diet; pain relief; spinal cord

\section{Introduction}

The mean and maximum lifespan in many different animal species can be increased by up to $50 \%$ simply by reducing their caloric intake while maintaining micronutrient intake or by increasing the period between foods, i.e., the intermittent fasting diet (IFD). This has been shown to be the case in many organisms commonly used in biomedical research, including Saccharomyces cerevisiae, Caenorhabditis elegans, mice, rats, and monkeys. In mammals, IFD reduces the development of age-related cancer (Raffoul et al., 1999), cardiovascular disease (Maeda et al., 1985), and deficits in immune function (Spaulding et al., 1997). Clinical and epidemiological studies in humans are entirely consistent with the beneficial effects of IFD. Overeating produces the opposite effects and increases the risk of many age-related diseases in humans (Lebovitz, 1999; Levi, 1999; Brochu et al., 2000). Although beneficial effects of IFD on cardiovascular, immune, and endocrine systems have been demonstrated, its effects on the nervous system were not systematically studied until recently. Emerging data suggest that a similar scenario may apply to neurodegenerative disorders, including Alzheimer's disease, Parkinson's disease, and stroke (Mattson et al., 2001). These effects could be the result of a complex neuroendocrine response, in

Received July 15, 2003; revised 0ct. 3, 2003; accepted 0ct. 9, 2003.

This work was supported by La Caixa Grant 00-032/00, Junta de Andalucía Grant CVI-122, and Direccion General de Investigacion Cientifica y Tecnica Grant BFI2002-00936. G.H.F. was a visiting fellow to the División de Neurociencias, under an Agencia Española de Cooperación Internacional fellowship. We thank Drs. J.F. Herrero, A. Múnera, and J. S. Taylor for critical reading of this manuscript, Dr. J. López-Barneo for the use of his radioactivity facilities, Dr. P. Navas for supplying the KOR antibody, and M. C. Sútil for technical assistance with animal housing.

Correspondence should be addressed to Dr. Ángel M. Carrión, División de Neurociencias, Universidad Pablo de Olavide, Carretera de Utrera, Kilometer 1, 41013 Sevilla, Spain. E-mail: amancar@dex.upo.es.

Copyright $\odot 2003$ Society for Neuroscience $\quad 0270-6474 / 03 / 2311120-07 \$ 15.00 / 0$ which are included the upregulation of trophic factors such as BDNF and IGF-1 (Anson et al., 2003).

The experience of pain in response to noxious stimuli serves a crucial biological purpose: it alerts a living organism to environmental dangers, inducing behavioral responses that protect the organism from additional damage. Since the discovery of an endogenous opiate system and the subsequent cloning of endogenous opioid ligands and their opiate receptors (for review, see Akil et al., 1996), which mediate the effects of the prototypic opioid morphine, an intense effort has been made to characterize the endogenous opiate system and to understand the physiological and pathophysiological roles of each of its components. The classical opiate system comprises three receptor types $(\delta, \mu$, and $\kappa)$ and their ligands encoded by the endogenous opioid genes proopiomelanocortin (pomc), proenkephalin (penk), and prodynorphin ( $p d y n)$, respectively. Because exogenous opioids such as morphine have traditionally been exploited for their analgesic properties, most studies have focused on the role of endogenous opioids in pain modulation, although participation in locomotive, cognitive, cardiovascular, neuroendocrine, and neuroimmune processes are known (Vaccarino and Kastin, 2000).

Here we show that animals maintained on IFD result in marked attenuation in pain behaviors regardless of the modality of the noxious stimuli (thermal or chemical) or the tissue type (cutaneous or visceral) affected. Activation of the dynorphinselective $\kappa$-opiate receptor was found to be causal to the reduced pain responses in IFD mice. Furthermore, we established that the increased activity in the spinal cord $\kappa$-opiate system inhibits the flow of nociceptive information to upper levels of the CNS. Thus, our findings document the molecular mechanism by which IFD downregulates the processing of nociceptive stimuli in the spinal cord, inducing analgesia. 


\section{Materials and Methods}

Animals. Experiments were performed on 6-week-old male Swiss mice weighing between 25 and $30 \mathrm{gm}$ and maintained under a $12 \mathrm{hr}$ light/dark cycle. Animals were divided into two groups: one group was fed ad libitum (AL), and the other was subjected to an alternate-day feeding regimen (i.e., dietary restriction). Mice were maintained on this feeding regimen for 3 months and then subjected to the treatment indicated below.

Behavioral studies of pain sensitivity. Behavioral studies were conducted in accordance with the guidelines of the European Union Council (86/609/EU) and following Spanish regulations (BOE 67/8509-12, 1988) for the use of laboratory animals in chronic experiments. Experiments were approved by the local institutional animal care committee. For the visceral pain test, mice were injected intraperitoneally with acetic acid $(0.6 \%, 5.0 \mathrm{ml} / \mathrm{kg}$ ) (Cao et al., 1998), and the number of abdominal writhes was counted from 20 to $30 \mathrm{~min}$ after the injection. For the hotplate test, a glass cylinder (16 cm high, $16 \mathrm{~cm}$ in diameter) was used to retain the mice on the heated surface of the plate, which was kept at a temperature of $55 \pm 0.5^{\circ} \mathrm{C}$. The time latency for paw licking was measured. The cutoff for licking responses was $15 \mathrm{sec}$. For pharmacological studies, naloxone hydrochloride ( $1 \mathrm{mg} / \mathrm{kg}$, i.p.; Sigma, St. Louis, MO), naloxona methiodide ( $2 \mathrm{mg} / \mathrm{kg}$, s.c.; Sigma), nor-binaltorphimine dihydrochloride (nor-BNI) (2 mg/kg, s.c.; Tocris Cookson, Ballwin, MO), naloxonazine dihydrochloride and 3-methoxynaltrezone hydrochloride mixture (7 and $1 \mathrm{mg} / \mathrm{kg}$, s.c.; Tocris Cookson and Sigma, respectively), and naltrindole hydrochloride ( $3 \mathrm{mg} / \mathrm{kg}$, s.c.; Sigma) were used. All drugs were administered $15 \mathrm{~min}$ before the beginning of the pain test. In all of the cases, two mice were tested simultaneously by an experienced observer blinded to both group and drug involved in the experiment.

$m R N A$ analysis by reverse transcription-PCR. Total RNA from brain tissue was extracted using Tripure reagent (Roche Products, Hertforshire, UK). A minimum of six animals per group, collected from at least two different experimental sessions, was used for each reverse transcription (RT)-PCR experiment. For RT-PCR, the following primers were used: 5' -CAAGTGAGTCAGAATGGCGTGG-3' and 5' -CCATGGAGGGGAAGTGTTATGC-3' ( pdyn); 5'-GGGTTTCAACGCCGACTACG-3' and $5^{\prime}$-CAGCTTGGGAAGGAGTCAGC-3' (c-fos); 5'-TGG TCA TGT TTG TCA TC- $3^{\prime}$ and $5^{\prime}$-CAT CAT CAG GAA ACT GCA- $3^{\prime}$ [ kor ( $\kappa$-opioid receptor)] and 5'-ATGTTCCAGTATGACTCCACTCACG-3' and $5^{\prime}$ GAAGACACCAGTAGACTCCACGACA-3' [gapdh (glyceraldehyde-3phosphate dehydrogenase)]. Arbitrary units of the ordinate axes in Figure 3, $A$ and $C$, and $4 A$ were computed as the ratio between the optical density band of the studied gene in the indicated cycle number and that of the gadph gene in the 15th amplification cycle. One unit was considered to be the ratio corresponding to the band with the lowest optical density of the studied gene in each experiment.

Electrophoretic mobility shift analysis. Nuclear extracts were prepared as described previously (Carrión et al., 1998b). Nuclear proteins were quantified, and extracts were immediately frozen in liquid nitrogen. Double-stranded oligonucleotides corresponding to the human DRE (downstream regulatory element) (5'-GAAGCCGGAGTCAAGGAGGCCCCTG-3') were labeled with $\left[\gamma^{-32} \mathrm{P}\right] \mathrm{ATP}$ and T4 polynucleotide kinase and used as a probe. Nuclear proteins $(5-10 \mu \mathrm{g})$ were incubated with a radioactive oligonucleotide probe $(100,000 \mathrm{cpm})$ for $20 \mathrm{~min}$ at room temperature in reaction buffer [10 mM HEPES, $\mathrm{pH} 7.9,10 \%$ glycerol, $0.1 \mathrm{~mm}$ EDTA, $8 \mathrm{~mm} \mathrm{MgCl} 2,1 \mathrm{~mm}$ dithiothreitol, $0.15 \mathrm{mg} / \mathrm{ml}$ poly $(\mathrm{dI}-\mathrm{dC})]$. Protein-DNA complexes were resolved in 5\% nondenaturing polyacrylamide gels and visualized by autoradiography.

Tissue preparation and immunohistochemistry. To analyze the induction of c-Fos immunoreactivity after visceral pain, five mice were taken from each experimental group after the writhing test and killed by decapitation $90 \mathrm{~min}$ after acetic acid injection. In addition, a group of five sham-paired mice pretreated with two injections of saline $(0.3$ and $0.1 \mathrm{ml}$ of saline at the indicated times for acetic acid or drug injection) was included as control. The spinal cord was removed by hydraulic pressure and placed on an ice-cold plate. The lower thoracic and upper lumbar segments were rapidly dissected out. The tissue was fixed by immersion in $4 \%$ paraformaldehyde in PBS for $24 \mathrm{hr}$ at $4^{\circ} \mathrm{C}$ and cryoprotected in
$30 \%$ sucrose PBS for $2 \mathrm{~d}$ at $4^{\circ} \mathrm{C}$. Spinal cords were embedded in $30 \%$ sucrose and kept at $4^{\circ} \mathrm{C}$ until cryotome sectioning. Coronal $50 \mu \mathrm{m} \mathrm{sec}-$ tions corresponding to T11 to L2 levels were obtained from each spinal cord and processed for free-floating immunohistochemistry (Taylor et al., 1998). The specific c-Fos antiserum (sc-52; Santa Cruz Biotechnology, Santa Cruz, CA) was used at a 1:4000 dilution. Immunostaining for KOR protein was done as for c-Fos, but this time, the KOR antibody (sc-9212) was diluted 1:500 and incubated $48 \mathrm{hr}$ at $4^{\circ} \mathrm{C}$.

Stereological and other quantitative analyses. Tissue sections were examined using dark-field microscopy to evaluate the spinal segmental level. A minimum of six sections from each mouse, from T11 to L2, was then examined with bright-field microscopy. The density of c-Fos- and KOR-positive cells was estimated by counting the number of positive neurons included in a grid placed in one ocular of a Leica (Bensheim, Germany) DMRB RFY HC microscope. A computer program for stereological quantification controlled the placement of the counting frame within a prescribed sampling area. The distance between sampling sites was $200 \mu \mathrm{m}$. The average area sampled per animal was $3 \mathrm{~mm}^{2}$. Spinal cord sections were analyzed by an experienced observer, who was blinded to both the group and the drug under analysis. The immunohistochemistry was performed for each experimental group and was repeated three times. Photomicrographs were taken from representative experiments. Statistical analyses were performed with the SPSS/PC+ package (SPSS, Chicago, IL). Unless otherwise indicated, mean values were calculated from $\geq 10$ measurements and from $\geq 5$ animals and are accompanied by their SEs.

\section{Results \\ IFD does not produce change in weight and motor activity}

Mice subjected to IFD were consuming essentially the same amount of food in a $48 \mathrm{hr}$ period as those fed AL. On the days they had access to food, the IFD mice ate approximately twice as much as did mice fed AL (data not shown). At the end of the study, the body weights of mice maintained on the IFD were similar to those of the AL-fed group $(40.6 \pm 1.05$ gm in AL group against $40.47 \pm$ $0.78 \mathrm{gm}$ in IFD group) (Fig. $1 A$ ). Furthermore, we evaluated the behavior of IFD mice. Animals maintained on IFD were indistinguishable from AL mice in locomotor responses under nonstressful conditions (locomotor activity box): activity values were $25.72 \pm 2.78$ broken beams/min during the first $5 \mathrm{~min}$ of the test in AL mice against $21.89 \pm 1.59$ broken beams/min in IFD mice (Fig. $1 B$ ).

\section{IFD induces analgesia in mice}

The response latency displayed in the hot-plate test for cutaneous thermal nociception by mice subjected to IFD was significantly longer than that by AL mice $(7.16 \pm 0.29 \mathrm{sec}$ in IFD mice against $4.17 \pm 0.18 \mathrm{sec}$ in AL mice; $p \leq 0.001$ ) (Fig. $2 A$ ). To determine whether this reduced nociceptive response in IFD mice was generalized to noxious stimulation in other tissues, we assessed acute visceral pain behavior evoked by the intraperitoneal injection of acetic acid, which produces a writhing response associated with an inflammatory reaction. IFD mice responded with significantly less abdominal writhing than did AL mice $(7.3 \pm 0.94$ stretches in IFD mice against $47.62 \pm 2.68$ stretches in AL mice; $p \leq 0.001$ ) (Fig. $2 \mathrm{~B}$ ). Because IFD and AL animals were indistinguishable in a locomotor activity box (Fig. $1 B$ ), the observed reduction in pain behavior evoked by noxious cutaneous and visceral stimuli appears to be attributable to a specific alteration in nociceptive processing rather than to a defect in motor functions in IFD mice.

\section{$\kappa$-Opiate receptor antagonist restores nociception in IFD mice}

Endogenous opioids and their specific receptors have been implicated in pain modulation (Dickenson, 1991; Suzuki et al., 
1999). Therefore, using a pharmacological approach, we investigated the functional relevance of the opiate system in IFDinduced analgesia. We injected the nonspecific opioid receptor antagonist naloxone hydrochloride into IFD and AL animals. Naloxone hydrochloride did not affect either the threshold to paw withdrawal in response to nociceptive thermal stimuli or the number of abdominal writhes in $\mathrm{AL}$ animals (Fig. $2 A, B$ ). In contrast, naloxone hydrochloride administration produced a recovery in pain behavior measurements in IFD mice $(3.96 \pm 0.39 \mathrm{sec}$ in AL mice against $4.49 \pm 0.28 \mathrm{sec}$ in IFD mice in the hot-plate test; or $42.7 \pm 4.94$ stretches in AL mice against $37.62 \pm 5.15$ stretches in IFD mice for visceral pain paradigm), resulting in nociceptive responses that were not distinguishable from those of AL mice (Fig. 2A,B).

The opiate system comprises three receptor types $(\delta, \mu$, and $\kappa)$ and their endogenous ligands, which are encoded by the opioid genes pomc, penk, and pdyn. To establish the specific opiate system involved in IFD-induced analgesia, we used the selective and specific opioid receptor antagonists naltrindole (for $\delta$ receptors), naloxonazine and 3-methoxynaltrezone mixture (for $\mu$ receptors), and nor-BNI (for $\kappa$ receptors). None of them affected painevoked behavior in AL mice. In IFD mice, only nor-BNI administration resulted in complete restoration of pain-evoked behavior $(3.89 \pm 0.29 \mathrm{sec}$ in AL mice against $4.32 \pm 0.48 \mathrm{sec}$ in IFD mice for hot-plate test latencies, and $42.75 \pm 10.68$ stretches in AL mice vs $41.4 \pm 9.36$ stretches in IFD mice in visceral pain paradigm) (Fig. 2C,D). These data suggest that there is an enhanced activation of $\kappa$-opioid receptors in IFD mice and that this activation is required to mediate the reduction of pain responses in these animals. These results do not preclude a possible stress-induced analgesia, which is mediated by a tonic activation of the $\mu$-opioid receptor (Rubinstein et al., 1996) and/or by a tonic activation of $\kappa$-opioid system (McLaughlin et al., 2003). Furthermore, stress-induced analgesia induced by a (putative) non-opioid system cannot be completely discarded.

\section{IFD provokes upregulation of} prodynorphin and $\kappa$-opiate receptor expression in spinal cord

Dynorphin-related peptides are the specific endogenous ligands for the $\kappa$-opioid receptor and are encoded by the $p d y n$ gene. For this reason, we analyzed the abundance of pdyn gene transcripts in the lumbar spinal cords of AL and IFD mice by semiquantitative RT-PCR. The basal expression of prodynorphin mRNA was markedly greater in lumbar spinal cord of IFD mice than of AL mice (Fig. $3 A$ ). In previous studies, the DREAM (downstream regulatory element antagonist modulator) protein has been implicated as a putative transcriptional repressor for the pdyn gene in cell cultures (Carrión et al., 1999; Campos et al., 2003) and in vivo

(Cheng et al., 2002). To analyze the activity of DREAM in lumbar spinal cord, we performed electrophoretic mobility shift assays. Nuclear protein extracts from spinal cord showed a single specific band as determined by competition assays (Fig. 3B, lanes 1-4).
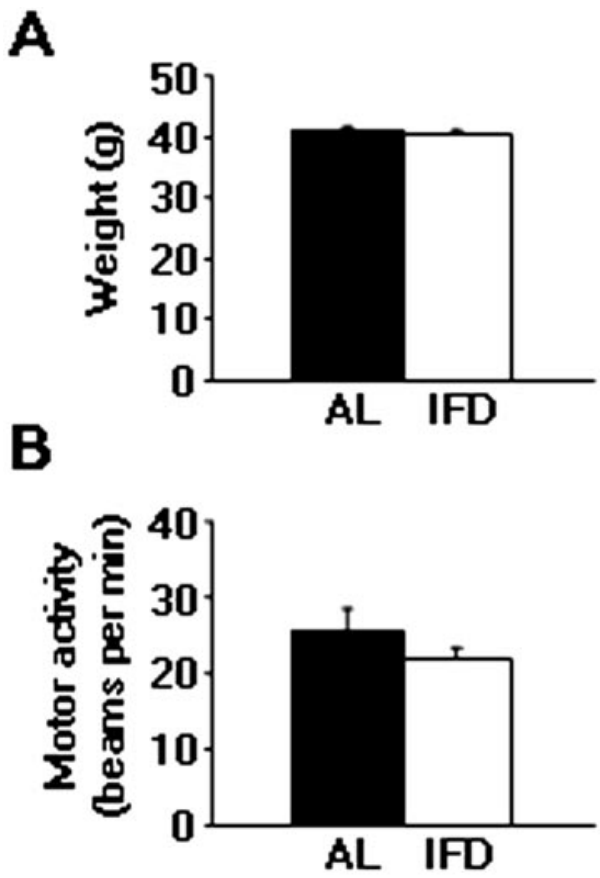

Figure 1. Weight and motor activity do not change in IFD animals. A, Weights (in grams) of AL and IFD animals after a 3 month diet. $B$, Locomotor activity of AL and IFD groups in nonstressful conditions. Activity is indicated as broken beams per minute. Filled bars represent AL mice, and open bars represent IFD mice. Mean values for weighs and motor activities were computed from $\geq 50$ animals per group. The statistical analysis was performed by two-tailed Student's $t$ test.
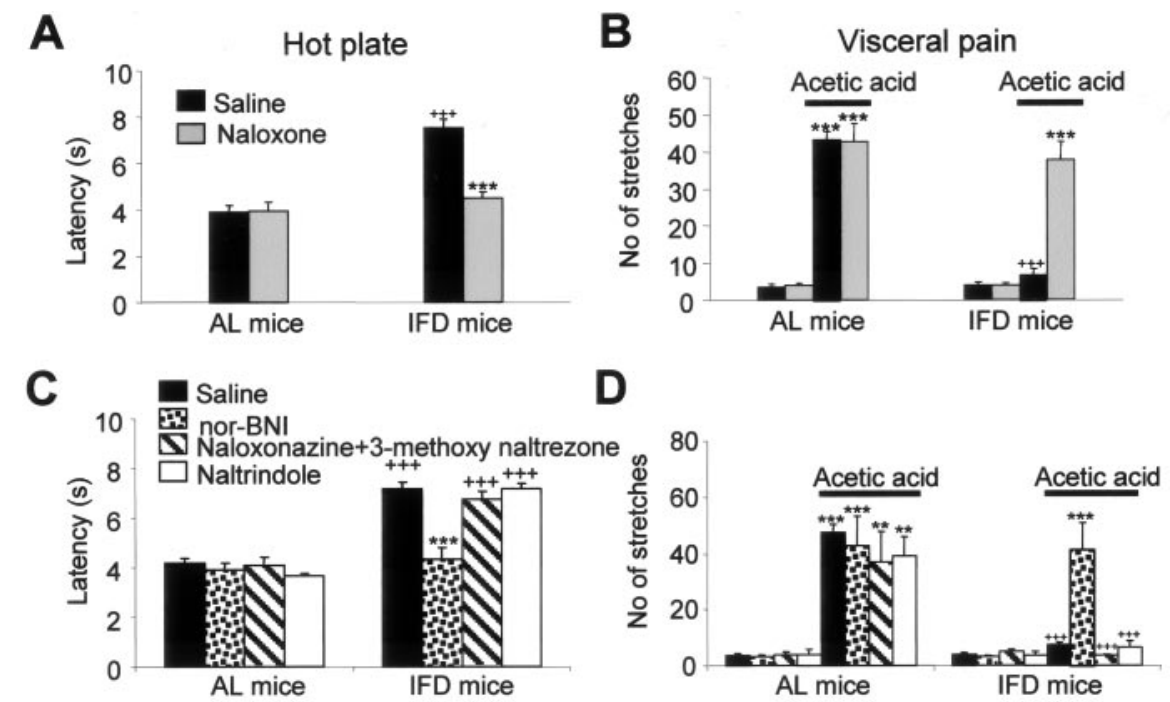

Figure 2. Analgesia induced by IFD is mediated by activation of $\kappa$-opioid receptors. $A, B$, Effects of naloxone hydrochloride (1 $\mathrm{mg} / \mathrm{kg}$, s.c., $15 \mathrm{~min}$ before each pain test) on the hot-plate test $(A)$ and visceral pain in response to acetic acid $(B)(0.6 \%)$ injection intraperitoneally. In the hot-plate test $(A)$, values represent the mean latency (in seconds) to paw licking, whereas in visceral pain $(B)$, values represent the number of abdominal stretches (writhes). C, D, Pharmacological analysis of IFD-induced analgesia in the hot-plate test $(C)$ and after acetic acid injection $(D)$. Injections of $2 \mathrm{mg} / \mathrm{kg}$ nor-BNI, 7 and $1 \mathrm{mg} / \mathrm{kg}$ of a naloxonazine and 3-methoxynaltrezone mixture, or $3 \mathrm{mg} / \mathrm{kg}$ naltrindole, were given subcutaneously $15 \mathrm{~min}$ before the pain test. In all of the tests, $n \geq 10$ animals per group. Experiments were repeated at least three times, and the number of mice per group in each experiment ranged from four to six. The statistical analysis was performed by one-way ANOVA and two-tailed Student's $t$ tests. ${ }^{+}$indicates statistical significance of the same treatments in groups AL and IFD; * indicates statistical significance of the different treatments with respect to vehicle in the same group; ${ }^{++},{ }^{* *} p \leq 0.01 ;{ }^{++},{ }^{* * *} p \leq 0.001$.

When we compared nuclear protein extracts from lumbar spinal cord, we detected a significantly lower DREAM activity in IFD than in AL mice tissues (Fig. 3B, compare lanes 5, 6). Interestingly, the levels of DREAM protein in lumbar spinal cord from 
A

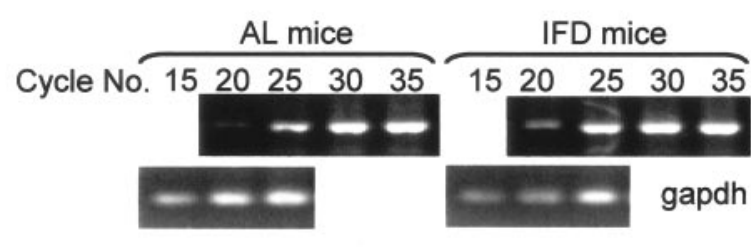

B

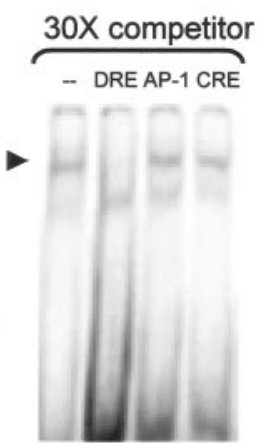

$123 \quad 4$

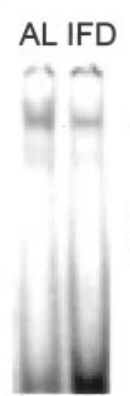

56
AL IFD
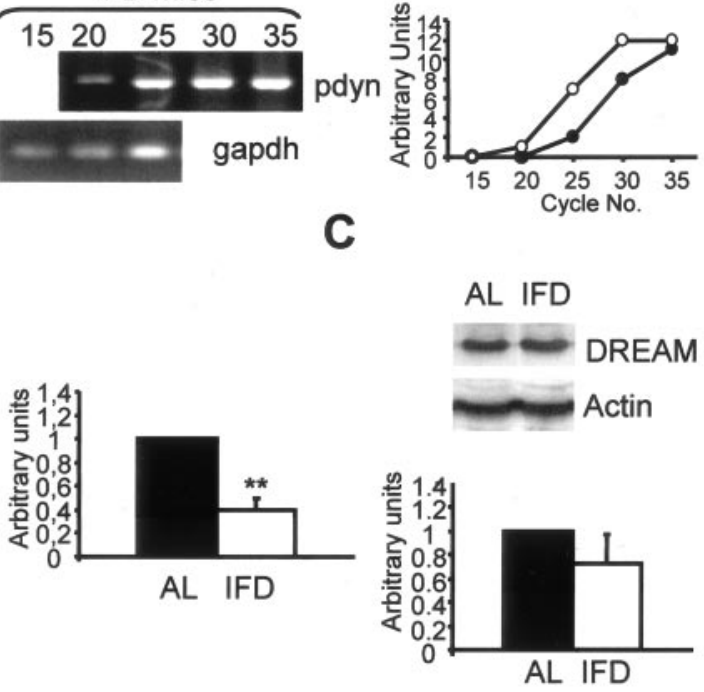

C
Figure 3. Prodynorphin and $\kappa$-opioid receptor expression are increased in the spinal cord of IFD mice. A, Basal expression of $p d y n$ mRNA in the spinal cord of AL and IFD mice, as assessed by semiquantitative RT-PCR. gapdh mRNA served as control. Graphs represent the relative abundance of prodynorphin-specific PCR products in the two animal groups (open circles, IFD mice; filled circles, AL mice). $B$, Competition of DREAM binding from lumbar spinal cord nuclear extracts of AL mice to DRE using 30-fold excess of wild-type, DRE, CRE (cAMP response element), and AP-1 (activator protein-1) cold sequences (lanes 1-4). The basal activities of DREAM protein from lumbar spinal cord of AL and IFD mice are also shown (lanes 5,6). The histogram represents the relative abundance of DREAM activity in the two groups. C, Western blot analyses of DREAM and actin expression in the lumbar spinal cord of AL and IFD mice. The histogram represents the relative abundance of DREAM protein in the two groups, expressed in arbitrary units. A total of $6-10$ animals was used for each experimental group. Animals were collected from three independent experiments.

A
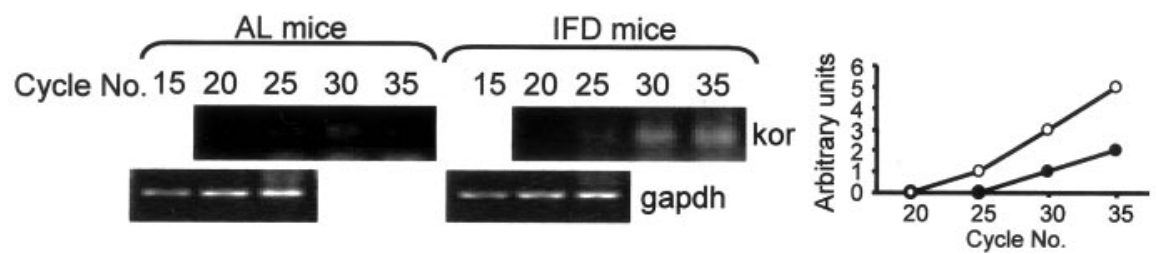

B

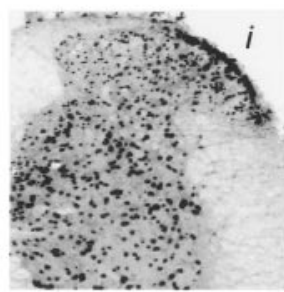

AL mice

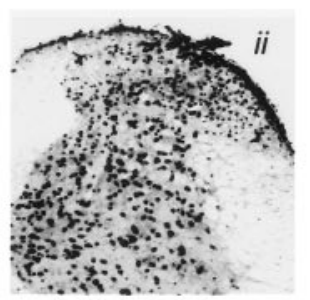

IFD mice

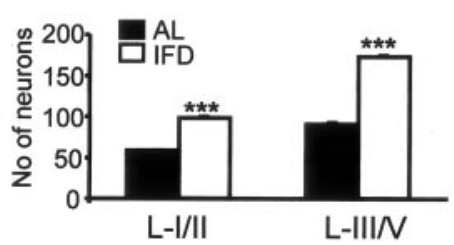

Figure 4. $\quad \kappa$-0pioid receptor expression is increased in the spinal cord of IFD mice. A, Basal expression of kor mRNA in AL and IFD mice spinal cord as assessed by semiquantitative RT-PCR. gapdh mRNA served as control. Graphs represent the relative abundance of kor-specific PCR products for AL (open circles) and IFD (filled circles) mice. B, Photomicrographs and immunohistochemical analyses of the expression patterns of $\kappa$-opioid receptor in the dorsal horn of lumbar spinal cord of AL ( $i$ ) and IFD (ii) mice. The histogram represents the number of positive neurons in laminas I-II and laminas III-V in each group (filled and open bars represent AL and IFD mice, respectively). We used $6-10$ animals per experimental group. These animals were obtained from three independent experiments. The statistical analysis was performed by one-way ANOVA and two-tailed Student's $t$ tests. Asterisks indicates statistical significance of the same treatments in groups AL and IFD. ${ }^{* * *} p \leq 0.001$.

IFD and AL animals were not significantly different (Fig. 3C). This may reflect a tonic activation of cAMP and/or of calcium transduction pathways in IFD mice. These signaling routes have been demonstrated to block DREAM activity (Carrión et al., 1998a, 1999; Ledo et al., 2000; Campos et al., 2003). In addition, we analyzed the levels of mRNA and protein for KOR. Using RTPCR strategy, we found an increase in kor mRNA in lumbar spinal cord from IFD compared with AL mice (Fig. 4A). Furthermore, immunohistochemistry analysis showed an increase in the KOR-positive neuron in whole spinal cord section except in the ventral spinal cord horn (Fig. 4B). Our data are consistent with the notion that $\kappa$-opioid receptors are tonically active in IFD mice. The absence of $\kappa$-opioid receptor downregulation in IFD mice provides additional support to our proposition that the analgesia observed in IFD animals is functionally mediated by these receptors (Laughlin et al., 2001).

\section{Prodynorphin blocks the nociceptive information flow through the spinal cord}

Nociceptive information is transmitted through a "pain pathway," which begins at the periphery, with the stimulusdependent activation of nociceptive terminals, runs through the spinal cord, and eventually reaches the brainstem and forebrain, in which the information is integrated to produce a "pain experience" (Woolf and Salter, 2000). Peripheral noxious stimulation induces the expression of various immediate early genes, including that of the c-Fos protein (Hunt et al., 1987; Herdegen et al., 1991). The physiological meaning of c-Fos protein induction is currently not known, and the specific targets for its secondary transactivation remain to be established (Munglani and Hunt, 1995). However, it has been associated with enhanced neuronal activation (Morgan and Curran, 1991). Intraperitoneal injection of $0.6 \%$ acetic acid in AL mice induced widespread c-Fos immunostaining in several segments of spinal cord, including T11 to L2 (Fig. 5A). The c-Fosimmunoreactive cell nuclei were distributed in the dorsal half of the spinal cord, preferentially in the superficial laminas I and II. Analysis of c-Fos-labeled neurons in AL mice revealed a significant $(p<0.001)$ induction of $c$-Fos in superficial dorsal laminas in animals injected with acetic acid (50.4 \pm 2.7 labeled neurons 90 min after the injection) compared with AL mice injected with isotonic saline (24.8 \pm 1.4 labeled neurons) (Fig. 5Ai, Aii). In contrast, the same visceral insult in IFD mice did not evoke an increase in the number of c-Fos-positive neurons in the superficial laminas of the dorsal horns $(25.5 \pm 1.99)$ compared with those labeled after isotonic saline injection $(27.6 \pm 1.43)$ (Fig. 5Aiii, Aiv). In addition, with the same experimental approach, we analyzed c-fos 
A
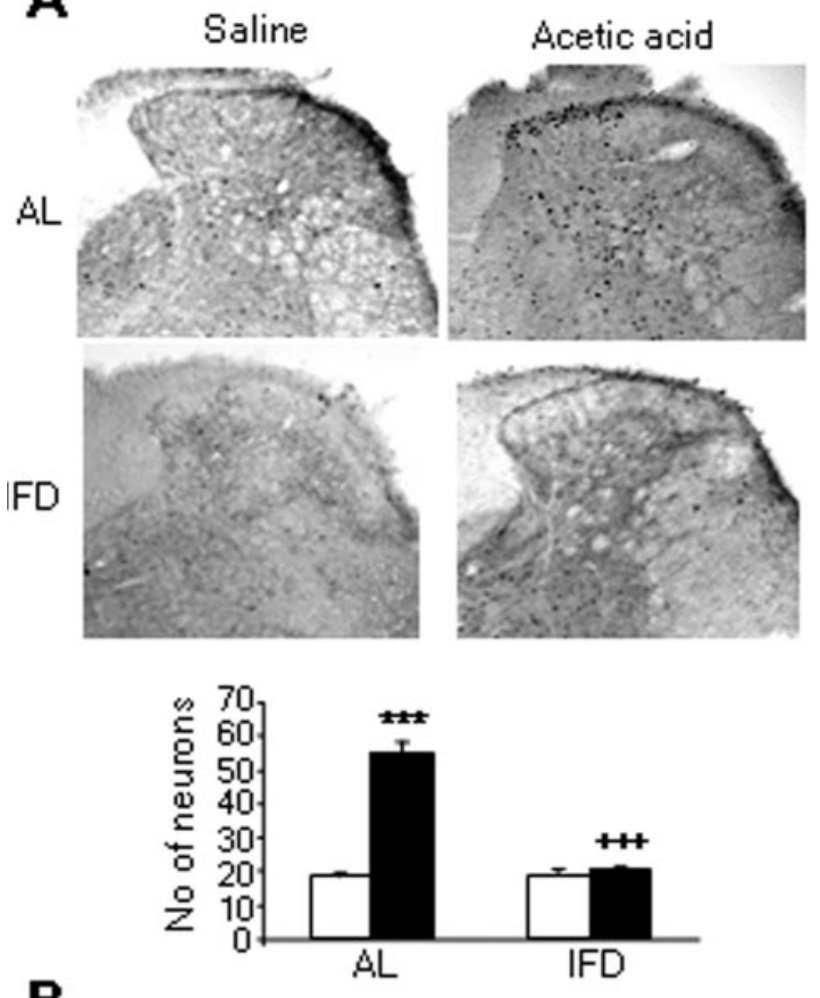

B

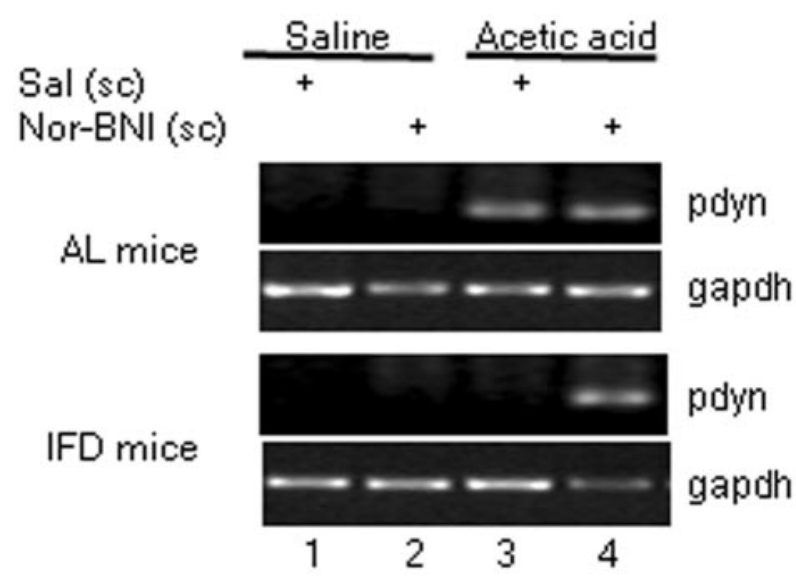

Figure 5. The $\kappa$-opioid system blocks neuron activation, as indicated by c-Fos expression, after nociceptive stimulation of the spinal cord in IFD mice. A, Photomicrographs and immunohistochemical analyses of the expression patterns of $\mathrm{c}-\mathrm{Fos}$ protein in the dorsal lumbar spinal cord of AL (i, ii) and IFD (iii, iv) mice 90 min after nociceptive treatment (ii, iv) or nontreatment $(i, i i i)$. The graph represents the number of positive neurons in each group. In the graph, filled bars represent nociceptive treatment, and open bars represent nontreated animals. $B$, Effect of nor-BNI on the c-fos mRNA transcription in thoracic and lumbar spinal cord after acetic acid injection in AL and IFD mice. gapdh mRNA served as control. We used six animals for each experimental group. These animals were obtained from three independent experiments. The statistical analysis was performed by two-tailed Student's $t$ test. ${ }^{+}$indicates statistical significance of the same treatments in groups AL and IFD; * indicates statistical significance of the different treatments with respect to vehicle in the same group; ${ }^{+++},{ }^{* * *} p \leq 0.001$.

mRNA levels 30 min after pain-evoking stimuli using RT-PCR. As in immunohistochemical experiments, nociceptive stimulation increased c-fos mRNA expression in thoracic-lumbar spinal cord in AL but not in IFD mice (Fig. 5B, lanes 1, 3). To establish the role of the $\kappa$-opioid system in the reduced induction of $\mathrm{c}-\mathrm{fos}$ expression in IFD mice after noxious stimulation, we studied c-fos expression after nor-BNI treatment. In this circumstance, acetic acid injection produced a similar increase in c-fos expression in AL and in IFD mice (Fig. 5B, lane 4). These results suggest that the tonic activation of the $\kappa$-opioid system could block the nociceptive information flow through the spinal cord. To confirm this idea, we investigated the activation of other brainstem nuclei included in the pain pathway. All the studied nuclei (parabrachial, dorsal raphe, and gray periaqueductal substance) were activated after nociceptive stimulation in AL but not in IFD mice (Fig. 6). These data clearly indicated that the activation of the $\kappa$-opioid system blocks the nociceptive information flow through the spinal cord.

Because results shown above did not preclude a possible effect of dynorphin peptide at a peripheral level, we performed a visceral pain experiment in the presence of naloxone methiodide, a pan-opiate receptor antagonist that does not permeate through the brain-blood barrier. Naloxone methiodide had no significant effect on the number of stretches produced by acetic acid administration of either (AL or IFD) animal group (Fig. 7). Indeed, the numbers of stretches induced by acetic acid after vehicle versus naloxone methiodide injection were $43.67 \pm 2.67$ versus $42.6 \pm 3.57$ in AL mice and $16.6 \pm 3.18$ versus $20.4 \pm 2.42$ in IFD mice. These data reinforce the proposal that analgesia induced by IFD occurs in the CNS at the spinal cord level. Thus, peripheral opiate receptor blockade did not have any significant effect on acute pain behavior in IFD mice. Hence, central $\kappa$-opiate mechanisms are required for the attenuated pain responses observed in IFD animals. The present evidence of an enhanced spinal prodynorphin mRNA suggests that the dynorphin/ $\kappa$-opiate receptor system of the spinal cord is likely mediating the analgesic responses induced by IFD. However, our data do not (completely) exclude a possible contribution of supraspinal opiate mechanisms on the observed pain behavior in IFD mice.

\section{Discussion}

Recent findings comparing different restriction diets suggest that many of the beneficial effects of IFD may result from a cellular stress response induced by the fasting state (Anson et al., 2003). For example, it was shown that levels of stress protein chaperones and neurotrophic factors are increased in rats and mice maintained on an IFD-feeding regimen. Some trophic factors (BDNF and IGF-1) have been implicated in the beneficial effects of dietary restriction. The different regulation of trophic factors in decreased-intake and IFD models of dietary restriction suggest that additional mechanisms must be operative. We report here that changes in the expression of the $\kappa$-opiate system could be important in the beneficial effects of IFD on nociceptive function. Furthermore, the IFD model could be an excellent tool for the study of molecular mechanisms involved in analgesia.

Several studies have provided support for an antinociceptive action of dynorphins. Dynorphin-mediated analgesia has been ascribed to the inhibitory action on neurons at $\kappa$-opioid receptors. Cumulative evidence suggests that dynorphin-induced activation of $\kappa$ receptors impairs synaptic transmission of nociceptive neurons (Randic et al., 1995) and diminishes substance-P release in the spinal cord dorsal horn (Zachariou and Goldstein, 1997). These putative presynaptic actions could be mediated by either enhancement of a hyperpolarizing potassium current (Grudt and Williams, 1993; Ogura and Kita, 2000) or suppression of selective calcium currents (Rusin et al., 1997; Wiley et al., 1997). All of these studies, together with our work, suggest a potential analgesic action of dynorphin. This effect may occur in 

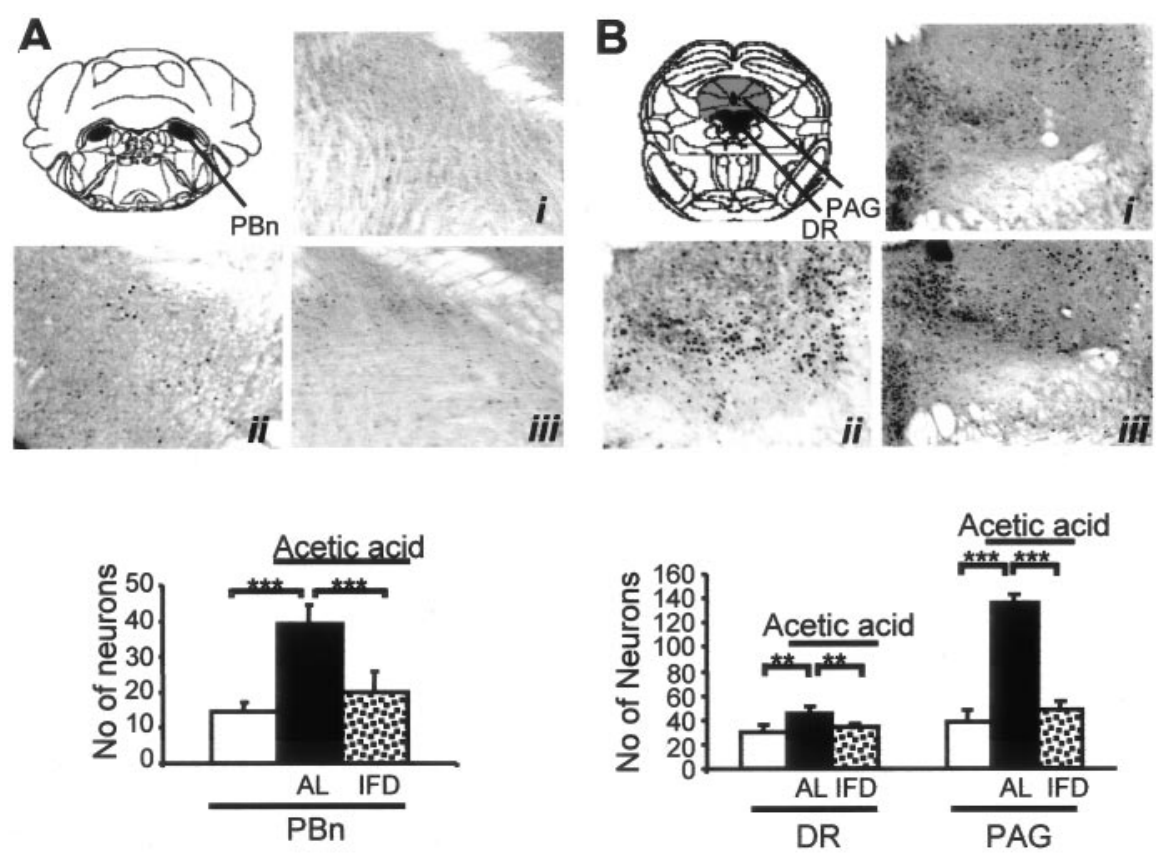

Figure 6. Absence of neuronal activation after noxious stimulation in brainstem nuclei of IFD mice. $A, B$, Photomicrographs and immunohistochemical analyses of the expression patterns of $c-F o s$ protein in the parabrachial nucleus ( $A ; P B n$, black), a relay station of the ascending pain pathway, and in the dorsal raphe ( $B$; DR, black) and gray periaquedultal substance (PAG; gray), components of the descending pain (modulatory) pathway of AL and IFD mice, 90 min after nociceptive treatment (ii is for AL, and iii is for IFD mice) or nontreatment ( $i$ ). Histograms represent the number of positive neurons in each group. Because nontreated AL and IFD mice showed equivalent c-Fos-positive neurons, both groups are considered here as the same group (open bars); black bars are for AL animals, and dotted bars are for IFD animals treated with acetic acid. A total of five animals per group, obtained from two independent experiments, were used. The statistical analysis was performed by one-way ANOVA and two-tailed Student's tests. ${ }^{*} p \leq 0.05 ;{ }^{* *} p \leq 0.01 ;{ }^{* * *} p \leq 0.001$.

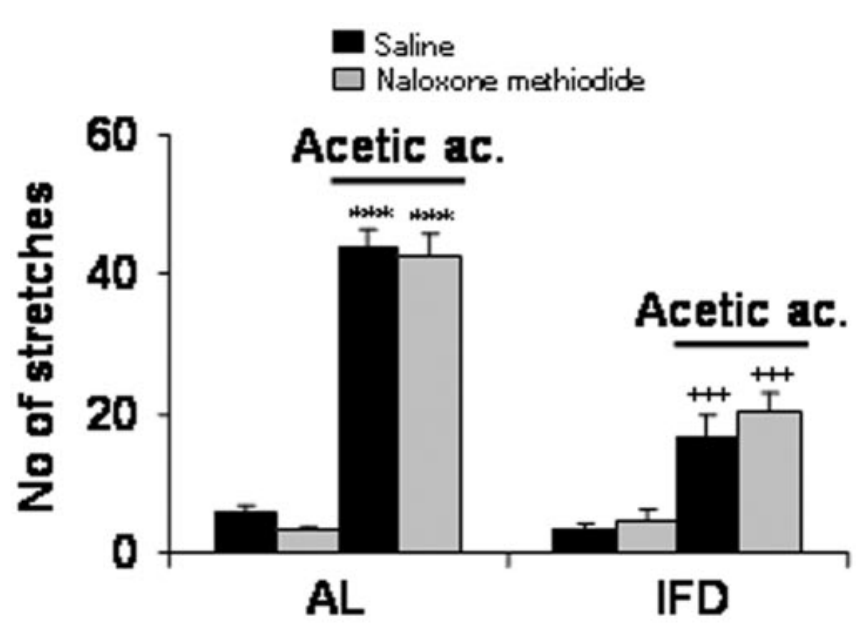

Figure 7. Peripheral mechanisms are not regulating anti-nociception induced by IFD. The effects of naloxone methiodide ( $2 \mathrm{mg} / \mathrm{kg}$, s.c.) on chemical visceral pain test were checked in AL and IFD mice. A total of eight animals per group was used. The statistical analysis was performed by two-tailed Student's $t$ test. ${ }^{+}$indicates statistical significance of the same treatments between groups AL and IFD; * indicates statistical significance of the different treatments with respect to vehicle in the same group; ${ }^{++},{ }^{* *} p \leq 0.001 ;^{+++},{ }^{* * *} p \leq 0.001$.

the dorsal horn of the spinal cord by $\kappa$-receptor-mediated negative modulation of synaptic transmission in nociceptive neurons.

Nevertheless, there are reports suggesting that dynorphins may exert pro-nociceptive effects, particularly in persistent pain states. Behavioral hyperalgesia resulting from inflammation (Iadarola et al., 1988) or nerve injury (Kajander et al., 1990) is accompanied by elevations in spinal dynorphin content. The increase in dynorphin has been considered causative of hyperalgesia, although the alternative (that this represents a negative feedback) has not been completely discarded.

The conflicting results indicating analgesic and pro-nociceptive effects of dynorphin have been reviewed recently(Caudle and Mannes, 2000). Immediately after an acute injury, dynorphin is released to bind to opioid receptors. This suppresses nociceptive inputs temporarily, so that the subject is subtracted briefly from the tissue-damaging situation. Accordingly, it can be inferred that dynorphin either produces analgesia or has anti-hyperalgesic and anti-allodynic effects. Once the immediate threat (the tissue-damaging situation) has been elapsed, the release of dynorphin should subside, and hypersensitivity (allodynia and hyperalgesia) takes over. The hypersensitivity would protect the injured area from additional damage by contributing to its immobilization. The anti-analgesic and anti-hyperalgesic actions of $\kappa$ receptors can be ascribed to the presynaptic inhibition of glutamate synaptic transmission (Bie and Pan, 2003). Alternatively, dynorphins may preferentially act on $\kappa$-opiate, or glutamate (NMDA), receptors, depending on their concentration. Thus, dynorphin concentration may determine the balance between pro-nociceptive and anti-nociceptive effects (for review, see Laughlin et al., 2001). It has been proposed that physiological concentrations of dynorphins are antinociceptive and neuroprotective through opiate receptor activation, whereas at extremely elevated levels, dynorphins are pronociceptive and even excitotoxic in an NMDA receptordependent manner (Hauser et al., 1999).

Prodynorphin expression is regulated by several transcription factors in a tissue-specific manner (Carrión et al., 1998b). cAMP response element-binding protein phosphorylation (Cole et al., 1995), c-Fos/c-Jun heterodimers (Naranjo et al., 1991), and DREAM (Carrión et al., 1999; Campos et al., 2003) are the main transcription factors implicated in $p d y n$ gene transcription. In the spinal cord, DREAM is the main regulator of $p d y n$ transcription (Cheng et al., 2002), as was demonstrated using null mutant mice for DREAM. These mice show dramatic analgesia in acute and chronic pain models. Our results are in agreement with those obtained with DREAM knock-out mice: in IFD mice, the increase in $p d y n$ transcription is mediated by a decrease in DREAM activity in the spinal cord. The change in DREAM activity in spinal cord neurons could play a pivotal role in the change of the genetic program that drives to analgesia in IFD mice. Current experiments, using IFD mice as tissue source, are aimed at finding the genes related to analgesia. In addition, our results with IFD mice, as well as those with mice containing null mutation for DREAM, reinforce the idea that DREAM activity inactivation would be an attractive therapeutic opportunity because both groups of animals show persistent analgesia (Costigan and Woolf, 2002).

Our results show that IFD induces an attenuation of pain responses in models of acute pain. The reduced pain behavior in IFD mice is attributable to enhanced $\kappa$-opioid receptor activity. 
These findings highlight a new aspect of pain modulation: namely, that the activation of $\kappa$-opioid receptors blocks nociceptive information flow at the dorsal horn of the spinal cord. Although biological functions other than nociceptive processing appeared not to be disturbed in IFD animals, in-depth studies must be done before $\kappa$ agonists can be proposed for use in pain treatment. Furthermore, these results suggest that intermittent fasting together with pharmacological treatment could be useful as a new therapeutic approach for pain.

\section{References}

Akil H, Meng F, Mansour A, Thompson R, Xie GX, Watson S (1996) Cloning and characterization of multiple opioid receptors. NIDA Res Monogr 161:127-140.

Anson RM, Guo Z, de Cabo R, Iyun T, Rios M, Hagepanos A, Ingram DK, Lane MA, Mattson MP (2003) Intermittent fasting dissociates beneficial effects of dietary restriction on glucose metabolism and neuronal resistance to injury from calorie intake. Proc Natl Acad Sci USA 100:2616-2620.

Bie B, Pan ZZ (2003) Presynaptic mechanism for anti-analgesic and antihyperalgesic actions of $\kappa$-opioid receptors. J Neurosci 23:7262-7268.

Brochu M, Poehlman ET, Ades PA (2000) Obesity, body fat distribution, and coronary artery disease. J Cardiopulm Rehabil 20:96-108.

Campos D, Jiménez-Díaz L, Naranjo JR, Carrión AM (2003) Ca-dependent prodynorphin transcriptional derepression in neuroblastoma cells is exerted through DREAM protein activity in a kinase-independent manner. Mol Cell Neurosci 22:135-145.

Cao YQ, Mantyh PW, Carlson EJ, Gillespie AM, Epstein CJ, Basbaum AI (1998) Primary afferent tachykinins are required to experience moderate to intense pain. Nature 392:390-394.

Carrión AM, Mellström B, Naranjo JR (1998a) Protein kinase A-dependent transcriptional derepression of the human prodynorphin gene via differential binding to an intragenic silencer element. Mol Cell Biol 18:6921-6929.

Carrión AM, Mellström B, Luckman SM, Naranjo JR (1998b) Stimulusspecific hierarchy of enhancer elements within the rat prodynorphin promoter. J Neurochem 70:914-921.

Carrión AM, Link WA, Ledo F, Mellström B, Naranjo JR (1999) DREAM is $\mathrm{a} \mathrm{Ca}^{2+}$-regulated transcriptional repressor. Nature 398:80-84.

Caudle RM, Mannes AJ (2000) Dynorphin: friend or foe? Pain 87:235-239.

Cheng HY, Pitcher GM, Laviolette SR, Whishaw IQ, Tong KI, Kockeritz LK, Wada T, Joza NA, Cracower M, Goncalves J, Sarosi I, Woodgett JR, Oliveira-dos-Santos AJ, Ikura M, van der Kooy D, Salter MW, Penninger JM (2002) DREAM is a critical transcriptional repressor for pain modulation. Cell 108:31-43.

Cole RL, Konradi C, Douglass J, Hyman SE (1995) Neuronal adaptation to amphetamine and dopamine: molecular mechanism of prodynorphin gene regulation in rat striatum. Neuron 14:813-823.

Costigan M, Woolf CJ (2002) No DREAM, no pain: closing the spinal gate. Cell 108:197-200.

Dickenson AH (1991) Mechanisms of the analgesic actions of opiates and opioids. Br Med Bull 47:690-702.

Grudt TJ, Williams JT (1993) $\kappa$-Opioid receptors also increase potassium conductance. Proc Natl Acad Sci USA 90:11429-11432.

Hauser KF, Foldes JK, Turbek CS (1999) Dynorphin A (1-13) neurotoxicity in vitro: opioid and non-opioid mechanisms in mouse spinal cord neurons. Exp Neurol 160:361-375.

Herdegen T, Kovary K, Leah J, Bravo R (1991) Specific temporal and spatial distribution of Jun, Fos, and Krox-24 proteins in spinal neurons following nociceptive trans-synaptic stimulation. J Comp Neurol 313:178-191.

Hunt SP, Pini A, Evan G (1987) Induction of c-Fos-like protein in spinal cord neurons following sensory stimulation. Nature 328:632-634.

Iadarola MJ, Brady LS, Draisci G, Dubner R (1988) Enhancement of dynorphin gene expression in spinal cord following experimental inflamma- tion: stimulus specificity, behavioral parameters and opioid receptor binding. Pain 35:313-326.

Kajander KC, Sahara Y, Iadarola MJ, Bennett GJ (1990) Dynorphin increases in the dorsal spinal cord in rats with a painful peripheral neuropathy. Peptides 11:719-728.

Laughlin TM, Larson AA, Wilcox GL (2001) Mechanisms of induction of persistent nociception by dynorphin. J Pharmacol Exp Ther 299:6-11.

Lebovitz HE (1999) Type II diabetes: an overview. Clin Chem 45:1339-1345.

Ledo F, Carrión AM, Link WA, Mellström B, Naranjo JR (2000) DREAM$\alpha$ CREM interaction via leucine-charged domains derepresses downstream regulatory element-dependent transcription. Mol Cell Biol 20:9120-9126.

Levi F (1999) Cancer prevention: epidemiology and perspectives. Eur J Cancer 35:1912-1924.

Maeda H, Glesier CA, Masoro EJ, Murata I, McMahan CA, Yu BP (1985) Nutritional influences of aging in Fisher 344 rats. II. Pathology. J Gerontol 40:671-688.

Mattson MP, Duan W, Lee J, Guo Z (2001) Suppression of brain aging and neurodegenerative disorder by dietary restriction and environmental enrichment: molecular mechanisms. Mech Ageing Dev 122:757-778.

McLaughlin JP, Marton-Popovici M, Chavkin C (2003) k-Opioid receptor antagonism and prodynorphin gene disruption block stress-induced behavioral responses. J Neurosci 23:5674-5683.

Morgan JI, Curran T (1991) Stimulus-transcription coupling in the central nervous system: involvement of the inducible proto-oncogenes fos and jun. Annu Rev Neurosci 14:421-451.

Munglani R, Hunt SP (1995) Proto-oncogenes: basic concepts and stimulation induced changes in the spinal cord. Prog Brain Res 104:283-298.

Naranjo JR, Mellström B, Achaval M, Sassone-Corsi P (1991) Molecular pathways of pain: Fos/Jun-mediated activation of the prodynorphin gene through a non-canonical AP-1 site. Neuron 6:607-617.

Ogura M, Kita H (2000) Dynorphin exerts both postsynaptic and presynaptic effects in the globus pallidus of the rat. J Neurophysiol 83:3366-3376.

Raffoul JJ, Guo Z, Soofi A, Heydari AR (1999) Caloric restriction and genomic stability. J Nutr Health Aging 3:102-110.

Randic M, Cheng G, Kojic L (1995) $\kappa$-Opioid receptor agonists modulate excitatory transmission in substantia gelatinosa of the rat spinal cord. J Neurosci 15:6809-6826.

Rubinstein M, Mogil JS, Japon M, Chan EC, Allen RG, Low MJ (1996) Absence of opioids stress-induced analgesia in mice lacking $\beta$-endorphin by site-directed mutagenesis. Proc Natl Acad Sci USA 93:3995-4000.

Rusin KI, Giovannucci DR, Stuenkel EL, Moises HC (1997) $\kappa$-Opioid receptor activation modulates $\mathrm{Ca}^{2+}$ currents and secretion in isolated neuroendocrine nerve terminals. J Neurosci 17:6565-6574.

Spaulding CC, Walford RL, Effros RB (1997) Caloric restriction inhibits the age-related dysregulation of the cytokines TNF-alpha and IL-6 in C3B10RF1 mice. Mech Ageing Dev 93:87-97.

Suzuki R, Chapman V, Dickenson AH (1999) The effectiveness of spinal and systemic morphine on rat dorsal horn neuronal responses in the spinal nerve ligation model of neuropathic pain. Pain 80:215-228.

Taylor J, Mellström B, Fernaud I, Naranjo JR (1998) Metamizol potentiates morphine effects on visceral pain and evoked c-Fos immunoreactivity in spinal cord. Eur J Pharmacology 351:39-47.

Vaccarino AL, Kastin AJ (2000) Endogenous opiates: 1999. Peptides 21:1975-2034.

Wiley JW, Moises HC, Gross RA, MacDonald RL (1997) Dynorphin A-mediated reduction in multiple calcium currents involves a Go alphasubtype $G$ protein in rat primary afferent neurons. J Neurophysiol 77:1338-1348.

Woolf CJ, Salter MW (2000) Neuronal plasticity: increasing the gain in pain. Science 288:1765-1769.

Zachariou V, Goldstein BD (1997) Dynorphin-(1-8) inhibits the release of substance P-like immunoreactivity in the spinal cord of rats following a nociceptive mechanical stimulus. Eur J Pharmacol 323:159-165. 